\title{
Desarrollo rural y agricultura familiar en Argentina: una aproximación a la coyuntura desde las políticas estatales
}

\author{
Rural development and family farming in Argentina: \\ an approach to the conjuncture from the state policies
}

Cristian Emanuel Jara ${ }^{1}$ (D), Ramiro Rodríguez Sperat ${ }^{1}$ Luis Felipe Rincón Manrique ${ }^{2}$ (D) y Andrea Gómez Herrera ${ }^{1}$

\begin{abstract}
Resumen: Sostener cuál ha sido el modelo (o los modelos) de desarrollo agrario que ha predominado en la Argentina en los últimos tiempos no es una tarea sencilla. Este artículo tiene por objetivo analizar la trayectoria del desarrollo rural en la República Argentina desde una mirada retrospectiva, prestando especial atención a cómo se ha concebido a la agricultura familiar. El eje argumental sostiene que las políticas agrarias, generalmente, han privilegiado a los modos de producción capitalistas en detrimento de los pequeños productores familiares de base campesina, quienes nunca terminaron de ser vistos como un sector productivo central en las dinámicas de desarrollo nacional. El texto se estructura en tres partes. En la primera, se presentan los diferentes modelos de desarrollo rural y el lugar de la agricultura familiar en las políticas estatales. Luego se especifican las transformaciones agrarias ocasionadas por la implementación de las políticas neoliberales, en el período que coincidió con el ajuste estructural en el país y el pos-consenso de Washington. Finalmente, se analizan algunas de las medidas tomadas por el gobierno actual y su impacto sobre la agricultura familiar. El texto consiste en una revisión de diversas fuentes documentales articulando distintas escalas temporales en el análisis.
\end{abstract}

Palabras-clave: desarrollo rural, políticas estatales, agricultura familiar, Argentina, neoliberalismo.

Abstract: To sustain what has been the rural development model (or models) that has predominated in Argentinean recent times is not a simple task. The objective of this paper is to analyze the trajectory of rural development in the Argentine Republic from a retrospective perspective, paying special attention

Data de submissão: 5 de fevereiro de 2018. Data de aceite: 22 de julho de 2018.

1. Universidad Nacional de Santiago del Estero (Unse), Ciudad de Santiago del Estero, Argentina. E-mail: cristianjara_cl@hotmail.com; ramirorodriguezsperat@hotmail.com; andreagh90@gmail.com

2. Corporación Colombiana de Investigación Agropecuaria (Agrosavia), Pasto, Mariño. Colombia. E-mail: feliperinconm@gmail.com 
to how family farming has been conceived. The main argument is that agrarian policies have generally privileged the capitalist production modes to the detriment of small peasant-based family farmers, who have never been seen as a central productive sector in the dynamics of national development. The text is structured in three parts. In the first one, the different models of rural development and the place of family agriculture in the state policies are presented. Then, the agrarian transformations caused by the implementation of the neoliberal policies in the period that coincided with the structural adjustment in the country and the post Washington's consensus are described. Finally, some of the measures taken by the current government and its impact on family farming are analyzed. The text consists of a review of various documentary sources, articulating different time scales in the analysis.

Key-words: rural development, public policies, peasant family farming, Argentina, neoliberalism.

Classificação JEL: E61.

\section{Introducción}

Las políticas estatales pueden ser entendidas como las acciones (e inacciones) del Estado para estimular, fortalecer o frenar un determinado modelo de desarrollo rural (Van der Ploeg et al., 2012). Estas constituyen un territorio de disputa en el que confluyen actores muy diferentes que ocupan distintas posiciones en la estructura social y con desiguales capacidades de incidir en el curso u orientación de estas acciones (para el caso del agro: campesinos, indígenas, pequeñas empresas familiares, grandes empresas agroexportadoras, sectores de la agroindustria, entre otros).

Los trabajos que se han ocupado de la temática concuerdan en señalar que en América Latina han existido diferentes modelos de desarrollo y que el paradigma neoliberal ha tenido una influencia dominante en las políticas gubernamentales de la región desde la década de 1970 (Kay, 2001, 2009; Morresi, 2011). Instituciones como el Fondo Monetario Internacional (FMI) o el Banco Mundial (BM) se encargaron de difundir estas ideas y presionaron a los países en vías de desarrollo a aplicar sus medidas (Jara et al., 2014).

Como contracara, estas medidas fueron perjudiciales para la agricultura familiar de base campesina. Algunos autores destacan que aquellas fueron generadas concibiendo a los agricultores familiares como objeto de políticas asistenciales más que productivas (De Dios, 1999; Rodríguez Enríquez \& Reyes, 2006), que propiciaron la concentración y la extranjerización de la tierra, atentando contra la seguridad alimentaria de los países (Jacoby, 2012; Rodríguez Sperat et al., 2015).

Para el caso de Argentina, el panorama no ha sido diferente: el giro aperturista y la aplicación de medidas liberales ortodoxas que se sucedieron posteriormente al golpe militar que derrocó a Perón en 1955 (fuertes devaluaciones, congelamiento de salario, reducción del gasto público), tuvieron diferentes etapas que terminaron por erosionar al modelo de Industrialización por Substitución de Importaciones (ISI). Sin embargo, fue recién a partir de la última dictadura cívico militar (año 1976) que se avanzó hacia la aplicación sistemática de políticas neoliberales, por vía de un modelo de valorización financiera y la reactualización del modelo agroexportador (López, 2006; Basualdo, 2006).

El gobierno de Raúl Alfonsín (1983-1989) en sus primeros años intentó resistir al avance del neoliberalismo, aplicando algunas medidas heterodoxas (Azpiazu et al., 2005). El fracaso de su programa económico gatilló una dinámica inflacionaria que desembocó en hiperinflación (Castellani, 2006; Pesce, 2006). La crisis económica de 1989-1990 allanó el camino hacia la reforma neoliberal. De hecho, la hiperinflación no sólo produjo un aumento de la tolerancia social hacia los ajustes económicos, sino que, además, trajo como resultado un importante descrédito del Estado como agente económico (Gerchunoff \& Torre, 1996).

Así, el advenimiento del neoliberalismo fue, poco a poco, instalando una política de ajuste estructural que derivó en el aumento de las desigualdades socioeconómicas mediante el repliegue del Estado en 
sus funciones redistributivas y de garante de la igualdad de oportunidades en materia de educación, salud y vivienda. Esta orientación fue profundizada por los dos gobiernos de Menem (1989-1995 y 1995-1999), y es en ese contexto que aparecen los impactos más regresivos sobre la situación socioeconómica de la población de menores recursos (Manzanal \& Schneider, 2011).

Los gobiernos kirchneristas (2003-2015) significaron una crítica a las políticas neoliberales, lo cual permitió poner en cuestión el sentido común del paradigma neoliberal y visibilizar demandas de sectores postergados hasta el momento (como el de la agricultura familiar de base campesina). Sin embargo, y particularmente para el sector agrario, este período no estuvo exento de ciertas tensiones en el sentido de, por un lado, no haber logrado avanzar en soluciones de fondo a algunos problemas estructurales, y por el otro, implementar políticas que terminaron favoreciendo a los grandes grupos de poder económico, cuestión sobre la que se profundizará más adelante.

La llegada de Mauricio Macri a la presidencia representó, para muchos, un regreso a la década de 1990, con políticas favorables a los grandes grupos de poder, la aplicación de medidas de ajuste y un paulatino retiro del estado como garante para los sectores sociales más vulnerables.

En el marco de esta coyuntura histórica compleja, sostener cuál ha sido el modelo (o los modelos) de desarrollo agrario que han predominado en la Argentina en los últimos tiempos no resulta una tarea sencilla. El presente trabajo intenta adentrarse en la problemática y, mediante una mirada retrospectiva, indaga sobre los modelos de desarrollo rural presentes en el dicho país, prestando especial atención a cómo se ha ido concibiendo a la agricultura familiar ${ }^{1}$ en el contexto.

\footnotetext{
1 En el caso de Argentina, las organizaciones que integran el Foro de Agricultura Familiar (FONAF) definieron a la agricultura familiar como " una forma de vida y una cuestión cultural, que tiene como principal objetivo la reproducción social de la familia en condiciones dignas, donde la gestión de la unidad productiva y las inversiones en ella realizadas es hecha por individuos que mantienen entre sí lazos de familia, la mayor parte del trabajo es aportada por los miembros de la familia, la propiedad de los medios de producción (aunque no siempre la tierra) pertenece a la familia, y es en su interior que se realiza la transmisión de valores, prácticas y experiencias" (Foro Nacional de la Agricultura Familiar, 2006, p. 9). El sector incluye una diversidad de actores (campesino, chacarero, colono, sin tierra, los trabajadores rurales y pueblos originarios) y actividades (productivas, extractivas y de servicios).
}

La hipótesis esgrimida consiste en que las políticas agrarias, generalmente, han privilegiado modos de producción capitalistas en detrimento de los pequeños productores familiares de base campesina, quienes nunca terminaron de ser vistos como un sector productivo central en las dinámicas de desarrollo nacional. Asimismo, se sostiene que el modelo neoliberal, a pesar de los cambios de gobierno en los últimos 30 años y pese a los cuestionamientos que recibió, no perdió vigencia en el país. Cabe aclarar que esto no implica desconocer los momentos de quiebre que existieron durante dicho período, ni tampoco la heterogeneidad de los procesos entre la región pampeana y extrapampena ${ }^{2}$.

A tales efectos, el relato histórico será construido a partir de fuentes secundarias y documentos periodísticos recientes, en lugar de otros métodos utilizados por los historiadores (Wald, 2016). Esta perspectiva analítica busca articular y poner en diálogo temporalidades múltiples (largo, medio y corto plazo), identificando "coyunturas críticas" en las acciones implementadas desde las esferas gubernamentales hacia el sector de la agricultura familiar. Además, el análisis multiescalar habilita el trazado de ciertos paralelismos y la identificación de aspectos disruptivos respecto a las políticas estatales agrarias en relación a la cuestión de la agricultura familiar en otros escenarios.

El artículo será desarrollado en tres partes. En la primera se presenta brevemente una mirada retrospectiva del lugar de la agricultura familiar en los diferentes modelos de desarrollo rural que subyacen en las políticas estatales. En segundo lugar, se especifican las transformaciones en el sector agrario ocasionada por la implementación de las políticas neoliberales en el período pos-consenso de Washington. Por último, se analizan algunas de las medidas tomadas por el gobierno de Mauricio Macri (entre 2015-2017) y su impacto sobre la agricultura familiar.

\footnotetext{
2 Las fértiles llanuras pampeanas se ubican en el centro del país. Tradicionalmente, han sido el núcleo industrial y se han caracterizado por el desarrollo de una agricultura orientada a la exportación. Ocupan en su mayor parte la provincia de Buenos Aires, el centro y sur de la provincia de Santa Fe, la mitad sureste de Córdoba y el este de La Pampa. En esta región, las economías campesinas han sido prácticamente eliminadas, mientras que el resto del país, principalmente en el noroeste se produjo la pervivencia de sistemas rurales de producción y reproducción no capitalistas como se analizará más adelante.
} 


\section{Una mirada de largo plazo}

Como se advirtió en la introducción, ha existido una fuerte tendencia en las políticas estatales a invisibilizar, marginar o excluir a la agricultura familiar de base campesina como un sujeto económico protagónico de los modelos de desarrollo rural. Esto marca una constante en las diferentes etapas de los procesos de acumulación capitalista que tuvieron lugar desde la conformación del Estado Argentino.

Durante el siglo XIX predominó un régimen alimentario centrado en Gran Bretaña, que combinaba la importación de granos básicos y ganado de las ex colonias inglesas (por ejemplo, Estados Unidos, Canadá, Australia), con la importación de productos tropicales de las colonias del Sur, reduciendo así el costo de la alimentación para la fuerza de trabajo en Europa. Este esquema, a su vez, facilitaba la acumulación del capital industrial, especialmente en Inglaterra, que pretendía ser el «taller del mundo». Este régimen se caracterizó por la emergencia de un mercado mundial para el trigo (McMichael, 2009).

Hasta 1880, Argentina disponía de amplias extensiones de tierras que eran potencialmente productivas, pero las mismas estaban habitadas por los pueblos originarios y eran de difícil aprovechamiento por parte del capital dadas las grandes distancias del territorio y debido a que la red de transportes cubría sólo una pequeña parte del país. Por otra parte, la entrada de capitales e inmigrantes era reducida, y la ganadería era la principal actividad, pero al realizarse de forma natural y con razas salvajes era considerada de baja calidad; el trigo, que era la principal mercancía transable internacionalmente, se importaba casi en su totalidad (Alonso \& Vázquez, 2008).

Teniendo en cuenta ese contexto, se comenzó a llevar adelante un proceso orientado a sentar las bases para que el país se insertara al mundo como proveedor de materias primas. Así, bajo la consigna de "orden y progreso", se comienza a dar un proceso que terminará consolidando un estado que sentó las condiciones políticas, jurídicas e institucionales necesarias para la expansión del capitalismo en el territorio argentino (Oszlak, 1997). En este período:

a) Se lleva adelante la "Conquista del desierto", una campaña militar realizada entre 1878 y 1885, por la que se avanzó sobre grandes extensiones de territorio de los pueblos originarios. De este modo, se incorporó al control efectivo del Estado Nacional una amplia zona de la región pampeana y de la Patagonia. Los pueblos originarios fueron sometidos y sufrieron la pérdida de sus tierras al ser deportados a reservas indias o trasladados para servir como mano de obra forzada.

b) Se promovió la inmigración de grandes masas de agricultores europeos: el Estado realizó una activa propaganda ofreciendo seguridades que en la época eran muy buscadas en Europa: paz y posibilidades de trabajo. En un principio se les daba facilidades a los inmigrantes, pero no se les garantizaba la posesión de las tierras que trabajaban.

c) Se multiplicaron los caminos, se instalaron líneas telegráficas y se comenzaron a incrementar la frecuencia de los viajes en barco.

d) De la mano de los avances tecnológicos, se instalaron los primeros frigoríficos en el país.

Así durante el período de 1880 a 1930 el modelo agroexportador fue el que predominó en nuestro país. La economía argentina comenzó a experimentar un rápido crecimiento por la exportación de sus materias primas provenientes, especialmente, de la ganadería. Esto marcó el principio de un período significativo de expansión macroeconómica. A finales del siglo XIX y comienzos del XX, se desarrollaron barcos frigoríficos que hicieron posible el transporte de carne refrigerada. Con los cambios en la producción y exportación, el país logró un crecimiento de su economía que le permitió situarse dentro de las mayores potencias mundiales. A finales del siglo XIX las exportaciones de cereales (maíz y trigo), que anteriormente se importaban, aumentaron fuertemente y se convirtieron en el principal producto del sector primario-exportador argentino.

La elite en el poder acompañó este proceso, adhirió al liberalismo económico; no obstante, en lo político fue conservador, pese a la vigencia de la formalidad republicana. En efecto, la oligarquía terrateniente ${ }^{3}$ que

3 La palabra "oligarquía" se trata de "una categoría política que designa una forma de ejercicio de la dominación, caracterizada por su concentración y la angosta base social, es decir, por la exclusión de la mayoría de la sociedad de los mecanismos de decisión política, es fundamentalmente coercitiva y cuando existe consenso de las clases subalternas, éste es pasivo" (Ansaldi, 1992, p. 3). Por consiguiente, la oligarquía no se trata estrictamente de una clase social sino de un modo de dominación que puede ser ejercida por clases, fracciones o grupos sociales diversos. 
gobernaba el país (Ansaldi, 1992) llevó a cabo un proceso de modernización excluyente bajo el imaginario de Argentina: granero del mundo, europea civilizada. Es decir: sin negros, ni campesinos, ni indios.

Si bien durante aquellos años, los gobiernos promovieron la inmigración de grandes masas de agricultores europeos, principalmente en la región del litoral, la especulación en el mercado de tierra termina con el proyecto de colonización. En efecto, una parte significativa de pequeños productores agropecuarios pasaron de colonos a arrendatarios (Romero, 2006). Las condiciones desfavorables de los contratos de alquiler de tierra en la Pampa Húmeda dieron lugar al Grito de Alcorta en 1912. Este episodio tuvo lugar en el sur de Santa Fe cuando una asamblea de pequeños productores declaró la huelga por tiempo indeterminado, reivindicando la rebaja general de los arrendamientos y aparcerías.

Otro proceso de resistencia a ese modelo de modernización excluyente se produjo en el Chaco en la reducción Napalpí en 1924 y consistió en la matanza de aproximadamente 200 indígenas de las etnias Qom y Mocoví por parte de la policía y grupos de estancieros. Allí los indígenas eran obligados a trabajar en condiciones de semi-esclavitud. En julio de 1924 se declararon en huelga, denunciando maltratos y explotación de los terratenientes (Vidal, 2008).

En el marco de una profunda crisis del sistema capitalista mundial, la década de 1930 va a poner de manifiesto las debilidades del modelo agroexportador por su dependencia respecto de los países industrializados, especialmente Inglaterra. En efecto, comienza a emerger un modelo desarrollo "hacia adentro" con el propósito de estimular la fabricación de productos que antes se importaban (Ferrer, 2005; Kay, 2001). De este modo, el Estado toma medidas proteccionistas orientadas a transferir divisa generada por el sector del agro-exportador a la industria, por ejemplo, mediante la elevación de los derechos aduaneros. Aquel esquema permitió consolidar el mercado interno y garantizar el acceso a productos manufacturados por parte de los trabajadores (Rapoport, 2006).

Uno de los momentos de mayor expansión del modelo ISI fue durante los dos primeros gobiernos de Perón (1946-1955). Anteriormente, se había impulsado el Estatuto del Peón Rural de 1944 con el propósito de mejorar las condiciones laborales del trabajador rural.
También en la Constitución del 1949 se consagró "la función social" de la tierra para promover la colonización en tierras fiscales y expropiación de algunos latifundios (con indemnización). Por otro lado, se sancionó una ley para facilitar el arrendamiento y los créditos para chacareros.

Pese al presupuesto peronista de que la función de la agricultura era alimentar a la clase obrera y subvencionar a la industria, en Argentina no se produjo una reforma agraria. La transformación estructural sobre la tenencia de la tierra no se hizo ni por razones de justicia social ni por razones de modernización contra la ineficiencia que representaba la pervivencia del latifundio ${ }^{4}$.

Por otro lado, cabe aclarar que el sujeto político interpelado por el peronismo no va a ser tanto el campesino indígena; sino el "descamisado" de una argentina industrializada, no pastoril (Svampa, 2009).

Aldo Ferrer (2005) señala que con el golpe de Estado de 1955 que derroca a Perón, parecía volverse atrás, pero hay una cierta inercia del proceso ISI que durará hasta 1976. La última dictadura cívico-militar que tomó el poder por la fuerza (entre 1976-1983) acentuó el desmantelamiento de las políticas orientadas a la protección y promoción de la industria nacional en nombre del libre comercio y la eficiencia productiva bajo el lema "Achicar el Estado es agrandar la nación".

Uno de los sectores corporativos que apoyó el golpe de Estado del 24 de marzo fue la Sociedad Rural Argentina $(\mathrm{SRA})^{5}$, la cual agrupa históricamente a sectores ligados al sector agroexportador. De hecho, José Alfredo Martínez de Hoz (miembro de una rica familia de estancieros, de formación neoliberal y ligado también al capital financiero internacional) fue el ministro de economía del gobierno de facto (Rapoport, 2006).

El giro aperturista de la dictadura puso fin al modelo ISI y produjo una redefinición del rol del Estado respecto del sector agrícola, impactando drásticamente sobre la

$4 \quad$ El latifundio alude a un tipo de finca tradicional de carácter extensivo, incluso insuficientemente explotada, donde solo una parte de las superficies útiles son cultivadas. "Lo que sorprende en las formas tradicionales y arcaicas del latifundio, es que se trata menos de una empresa productiva que de una institución social y hasta política, poco sensible a la coyuntura económica" (Rouquié, 2000, p. 89).

5 Sociedad Rural Argentina (SRA) es una entidad patronal fundada en 1866 que agrupa principalmente a grandes propietarios de tierras en la región pampeana, dedicados a la agricultura y la ganadería. Históricamente ha tenido un importante papel político y económico. 
agricultura familiar de base campesina. Al respecto, es importante mencionar que en este período surgen las Ligas Agrarias (entre fines de 1960 y 1970), como respuesta a condiciones desventajosas a las cuales se enfrentaban los pequeños y medianos agricultores en relación a los monopolios, buscando disputar los términos de inclusión en el mercado (Roze, 1992). Si bien las ligas son un antecedente de muchos movimientos campesinos que surgen en los 90, existe una diferencia sustancial: en la década de 1960 y 1970 las demandas de los chacareros de las ligas agrarias eran más bien comerciales (inclusión marginal) mientras que los noventa el problema de los movimientos campesinos será la exclusión, lo cual se materializará especialmente en desalojos de familiar campesinas e indígenas de las tierras que habitaron ancestralmente.

Algunas de las características de las trasformaciones tuvieron continuidad pese al retorno de la democracia en 1983, creando las condiciones de posibilidad para el resurgimiento del modelo agroexportador y extractivista a principio del siglo XXI. Esto será objeto de análisis del siguiente apartado.

\section{Los primeros programas de desarrollo rural en el contexto de hegemonía neoliberal}

El agro argentino ha sido escenario de cambios profundos durante los años noventa. Uno de ellos se relaciona con la reducción del estrato de Explotaciones Agropecuarias (EAPs) de menor superficie. En este sentido, el Censo Nacional Agropecuario del año 2002 arrojó datos preocupantes sobre el nivel de concentración de la tierra: el $60 \%$ de las explotaciones agropecuarias más pequeñas no llegaba a poseer ni el $5 \%$ de la tierra, mientras que el 10\% de las explotaciones agropecuarias más grandes concentraba el 78\% de la misma (Slutzky, 2008).

En la región pampeana la difusión del cultivo de soja y el alza en los precios internacionales trajeron aparejados importantes cambios. Los productores pequeños o medianos que no podían acceder a las nuevas tecnologías, cedieron sus tierras y se transformaron en "pequeños rentistas" (Gras \& Hernández, 2010) o bien las vendieron. Estas figuras conllevaron a una desvinculación del propietario de la tierra de las actividades productivas y el ingreso de capitales que no provienen del sector (como ser los pools de siembra y fondos de inversión agrícola). En consecuencia, se produjo una concentración en el uso de la tierra, independientemente de la propiedad de la misma. Dicho fenómeno se potencia merced al aumento del precio de los commodities, que se ve reflejado en el aumento del precio de la tierra. En efecto, el valor de la hectárea ha experimentado un aumento de hasta un 600\% desde 1998 al 2011 (Gigena et al., 2013).

En las regiones extrapampeanas, la tierra también aumentó su valor. Sin embargo, no solo se produjo un aumento de su precio en zonas arables, sino que también se incorporaron nuevas superficies a partir del desmonte, con los consiguientes conflictos que ello acarrea debido a la inseguridad en la tenencia, desalojos de familias y éxodo de población rural. El caso de Santiago del Estero, una provincia del noroeste del país, resulta ejemplificador, pues allí existen alrededor de 10.000 explotaciones agropecuarias sin límites definidos (Paz, 2006). Es decir, familias que poseen la tierra con ánimos de dueño pero que no cuentan con sus títulos de propiedad, lo cual ha dado lugar a continuos conflictos por el control sobre dicho bien natural. En este contexto, los campesinos santiagueños han desarrollado mecanismos de resistencia. Así, el 4 de agosto de 1990, con el nacimiento del Movimiento Campesino de Santiago del Estero (MOCASE), se manifiesta una de las más importantes expresiones de organización en la lucha por la tierra.

Al igual que en otros lugares de América Latina, la expansión del cultivo de soja en el norte argentino produjo el reemplazo de cultivos tradicionales, como el algodón y el maíz, mediante la incorporación de nuevas tierras al proceso productivo. Esto implicó no solo desalojos de campesinos sino también prescindir de mano de obra rural, la cual tenía una importancia central, por ejemplo, en el cultivo de algodón.

A mediados de la década del ochenta se implementaron algunos programas para la agricultura familiar que sentaron precedentes en las dos décadas posteriores. Uno de ellos fue el Programa de Apoyo a los Pequeños Productores del Noroeste Argentino (PNOA) que se ejecutó conjuntamente entre gobierno nacional y gobiernos provinciales. Otro fue el Programa de Integración a la Mujer Rural (con financiamiento de la Organización de las Naciones Unidas). Estas políticas, que funcionaron en articulación con organizaciones no gubernamentales, tuvieron como población objetivo al segmento de pequeños productores -especialmente del 
noroeste argentino- y entre sus principales lineamientos de intervención se encontraban la incorporación de tecnología, la capacitación y la organización de los productores (Lattuada et al., 2015).

En los noventa se implementaron programas similares dirigidos a los pobres rurales, como el Programa de Pequeños Productores del Noreste Argentino (PNEA), el Programa de Desarrollo Rural del Noreste Argentino (PRODERNEA), el Programa Social Agropecuario (PSA) y el Programa de Iniciativas de Desarrollo Rural (PROINDER), pretendiendo el mejoramiento de los ingresos a este sector. No obstante, aquellas estrategias estaban en tensión con las políticas macroeconómicas de los gobiernos menemistas (1989-1999) que conllevaban una reducción sustancial de la cobertura de los programas de crédito, asistencia técnica o comercialización a los pequeños productores (Manzanal \& Schneider, 2011). Una de las exigencias de los programas de alivio a la pobreza rural, promovidos por los organismos internacionales de financiamiento, fue la focalización de los potenciales beneficiarios de los programas vinculados con la pobreza. Esto significaba definir la población, su importancia y su localización, lo cual resultaba complejo, dada la gran diversidad de realidades que componen el universo de la producción familiar agropecuaria.

En suma, las políticas públicas dirigidas hacia la agricultura familiar gestadas al calor del paradigma neoliberal se centraron en créditos, subsidios y/ o apoyo técnico-productivo, pero sin avanzar en cuestiones medulares para el sector como por ejemplo romper con las restricciones que opone un mercado concentrado de alimentos o asegurar el acceso a la tierra a los productores familiares (Rodríguez Sperat, 2015). Asimismo, dichas políticas carecieron de diagnósticos regionales que indiquen las acciones específicas y prioritarias a realizar en cada zona. Por otra parte, los montos de crédito o subsidio eran insuficientes para salir de una situación de pobreza estructural.

\section{La agricultura familiar se instala en la agenda pública}

La crisis política y económica de 2001 fue seguida por un proceso complejo de protestas sociales y depresión económica que se fue morigerando con la implementación de políticas sociales, represivas y un profundo ajuste económico (que incluyó devaluación, licuación de pasivos públicos y privados, otorgamiento de prioridad al superávit fiscal y contención del gasto público). Luego de la renuncia del Presidente De La Rúa (1999-2001) se produjo una lenta pero sistemática reconstrucción del poder gubernamental y un paulatino aceleramiento de la economía 6 .

Así, a inicios de 2003 se celebraron elecciones presidenciales donde surgió electo Néstor Kirchner (2003-2007). Huérfano de apoyos electorales claros (había obtenido el 22\% de los votos en la primera vuelta electoral) y de soporte partidario (el peronismo se encontraba quebrado en al menos tres partes). Fue así que, en una primera instancia apostó por medidas de alto valor simbólico asociadas a las demandas de la izquierda y el progresismo, tales como un giro en materia de derechos humanos y el recambio de figuras desprestigiadas en el poder judicial. Paralelamente, y en el marco de la negociación por una quita importante en la deuda, el nuevo Presidente adoptó un tono enfático contra los representantes nacionales e internacionales del modelo neoliberal (Morresi, 2015). Sin embargo, el discurso confrontativo del gobierno estuvo, en general, acompañado por decisiones moderadas en el campo económico ${ }^{7}$ (Novaro, 2006).

Cabe destacar que en ese mismo período se evidencia un alza muy importante de los precios internacionales de productos primarios como la soja y del petróleo (2003-2005, período que se extendió hasta el 2012), lo cual terminó de reactivar la economía nacional (Altomonte \& Sánchez, 2016)

El éxito en la recuperación económica le permitió a Kirchner fortalecer su posición. En ese nuevo contexto, se elevó aún más el tono de confrontación con el modelo

\footnotetext{
6 Algunos de los factores externos que propiciaron estas mejoras fueron las subas de los precios de las commodities y las bajas en las tasas de interés internacionales (Morresi, 2015).

7 Se negocia con el tesoro norteamericano las condiciones para una disminución de la deuda externa, se procede a un proceso de desendeudamiento con el FMI, el Presidente Kirchner realiza una gira por Europa y Estados Unidos en busca de apoyos internacionales, entre los que se destacaran las declaraciones de George Bush en favor de las negociaciones argentinas con el FMI (Fondo Monetario Internacional) (Montero \& Vincent, 2013), al tiempo que busca apoyos incorporando a políticos conservadores (provenientes de la UCD) y tejiendo una alianza con los "barones" del conurbano bonaerense (Varesi, 2014).
} 
neoliberal y comenzaron a desplegarse algunas medidas concretas en este mismo sentido, como la conformación de un bloque de países contrarios a la implementación de un Área de Libre Comercio Americana (ALCA) y algunas estatizaciones de empresas privatizadas durante los años noventa (como por ejemplo el Correo Argentino y Aguas Argentinas).

No obstante, fue sólo después del año 2007, durante la presidencia de Cristina Fernández de Kirchner (2002-2011), que se desarrollaron políticas públicas claramente contrarias al neoliberalismo (Morresi, 2015). Durante los dos mandatos de Cristina Fernández 2007-2015 se implementó la estatización de los fondos de jubilaciones y pensiones y un avance progresivo de las capacidades regulatorias del Estado. En efecto, se avanzó en una agenda que incluyó políticas masivas de reparación social, como la Asignación Universal por Hijo (AUH) ${ }^{8}$ y la creación de la Subsecretaría de Agricultura Familiar con la misma estructura institucional del Programa Social Agropecuario, y la aprobación de leyes de alto impacto en términos de derechos civiles, como la ley de matrimonio igualitario.

Es en ese contexto que, desde las esferas gubernamentales nacionales, se comienza a observar una renovada atención en torno a la agricultura familiar (Márquez, 2007). Simultáneamente, esta visibilización entra en tensión con el reposicionamiento de Argentina en el mercado mundial como proveedor de productos primarios, en un contexto internacional de principios de siglo XXI caracterizado por el aumento de la demanda de materia prima por parte de países como China, India o Rusia.

Eduardo Gudynas denomina neoextractivismo a la reactualización de

un estilo de desarrollo basado en la apropiación de la naturaleza, que alimenta un entramado productivo escasamente diversificado y muy dependiente de una inserción internacional como proveedores de materias primas, y que si bien el Estado juega un papel más activo... se repiten los impactos sociales y ambientales negativos (Gudynas, 2009, p. 188).

8 Es una asignación que se perciben los padres (teniendo la prioridad la madre) cada mes por cada hijo menor de 18 años (hasta 5 hijos) o bien por cada hijo con alguna discapacidad sin límite de edad. Quienes perciben son desocupados y trabajadores no registrados, del servicio doméstico, monotributistas sociales, inscriptos en los programas de empleo de los ministerios de Desarrollo Social y de Trabajo de la Nación.
En otras palabras, el Estado argentino, en los últimos tres lustros, ha jugado un papel dual: por un lado, ha facilitado la acumulación, y por el otro, ha tratado de mantener determinados niveles de legitimidad. Es decir, se mantuvo una institucionalidad que permitirá la concentración de tierra a gran escala mediante leyes, beneficios impositivos, créditos favorables a las empresas transnacionales, pero simultáneamente, se tuvieron que fijar algunos criterios distributivos para garantizar la gobernabilidad (Borras et al., 2013).

La creación del Foro Nacional de la Agricultura Familiar (FONAF), en agosto del 2006, con participación de representantes de numerosas organizaciones del campo, generó los lineamientos sobre políticas públicas orientados al diseño de un plan estratégico para la Agricultura Familiar. Algunas de las respuestas del sistema político a las demandas del sector, tuvieron como resultado la sanción de importantes normativas tales como la Ley de Propiedades comunitarias indígenas № 26.160 (que suspende los desalojos en tierras comunitarias indígenas y dispone realizar un relevamiento a nivel nacional), la Ley $\mathrm{N}^{\circ} 26.331$ (de ordenamiento territorial de los bosques nativos) y la Ley $\mathrm{N}^{\circ} 26.737$ (que pone límites a la compra de tierra por extranjeros).

A su vez, la Ley N²7.118, de "Reparación Histórica de la Agricultura Familiar para la construcción de una nueva ruralidad", tuvo como propósito una asignación presupuestaria específica para la promoción de políticas de infraestructura rural y prevé medidas tendientes a garantizar el acceso a la educación, la salud y los servicios públicos. Sin embargo, la ley fue aprobada sin presupuesto y no se reglamentó debido a disputas interna del bloque político que la promovió (Nogueira et al., 2017).

La rapidez en la que los productores se identificaron con la categoría "agricultor familiar" se relacionó fundamentalmente con la posibilidad de acceso a políticas públicas. Asimismo, el conflicto agrario de 2008, que ocasionó las retenciones del Estado a las exportaciones de granos, contribuyó a la instalación del término agricultura familiar en la agenda del gobierno nacional (Jara, 2016). $\mathrm{Al}$ año siguiente, se crea la Subsecretaría de Agricultura familiar. Asimismo, cabe mencionar que en el seno del INTA (Instituto Nacional de Tecnología Agropecuaria) se puso en funcionamiento el Centro de Investigación para la Pequeña Agricultura Familiar (CIPAF), el cual se creó el 26 de agosto de 2005 con el objetivo de generar, adaptar y validar tecnologías apropiadas para el desarrollo sostenible del sector. 
No obstante, y pese a los logros que obtuvo este actor agrario disputando los recursos del Estado, no fue suficiente para posicionarse a nivel de políticas de desarrollo rural como un sujeto productivo. En este sentido, resulta ilustrativo el Plan Estratégico Agroalimentario y Agroindustrial Participativo y Federal (PEA) presentado por el Poder Ejecutivo Nacional en 2011, el cual era una apuesta a modelo agroexportador a gran escala: "Estamos convencidos que el desafío es incrementar la productividad con mayor valor agregado, más empleo, más exportaciones" (Argentina, 2011, p. 28). Al respecto Carballo González et al. (2012) sostienen que el sector no llega a ser lo suficientemente visibilizado en sus aportes, capacidad de generar riqueza y promover el desarrollo. Desde esta perspectiva, los pequeños productores serían entonces sujetos pasibles de políticas sociales, pero no de políticas productivas.

Asimismo, en agosto de 2012, el ministro de agricultura Norberto Yauhar, presentó la nueva soja (RR2) junto a los directivos de Monsanto. En aquella ocasión exhortó a "respetar la propiedad intelectual" e informó que se estaba trabajando en una nueva ley de semillas que contemple el cobro de regalías para quienes desarrollan las semillas transgénicas. Mientras tanto, las organizaciones se manifestaron reivindicando el derecho a guardar parte de la cosecha para la próxima siembra, aduciendo que, bajo el argumento de respetar la "propiedad intelectual", la nueva ley limitaría el derecho histórico al "uso propio" (Aranda, 2012).

Otro cambio significativo, en este contexto, fue el ímpetu que tomaron los enfoques territoriales de intervención en las diferentes agencias estatales del desarrollo rural, principalmente el Inta y la Subsecretaría de Desarrollo Rural y Agricultura Familiar de la Nación. La propuesta del Desarrollo Territorial Rural (DTR), cuyos principales lineamientos fueron elaborados por Shejtman y Berdegué, investigadores del Rimisp (Centro Latinoamericano para el Desarrollo Rural) fue en gran medida adoptada por el INTA. El principal supuesto es que el desarrollo, entendido como un proceso de trasformación productiva e institucional, involucra la multiplicidad de actores (públicos y privados) que operan en el territorio local a partir de lazos de cooperación y articulación con actores que operan a escala regional o nacional (Shejtman \& Berdegué, 2004; Lattuada et al., 2015).

Por otra parte, la Subsecretaría de Desarrollo Rural y Agricultura Familiar de la Nación adoptó el Enfoque
Socio-Territorial Integral que implicaba abordar las necesidades específicas de los actores que operan en el territorio y promover la participación directa de los agricultores familiares en la definición de políticas públicas inclusivas. Entre sus ejes prioritarios de intervención se encontraban la soberanía alimentaria local y regional, las políticas de tierra, agua y hábitat, como también el ordenamiento territorial y fortalecimiento institucional.

En suma, la Agricultura Familiar pudo ser instalada en la agenda política en los últimos tiempos, haciendo visible las demandas del sector. Durante los años de gobierno kirchnerista se observó un reconocimiento por parte del Estado, lo cual se expresó por ejemplo en un aumento de las líneas de crédito y subsidio hacia el sector. Sin embargo, no se logró avanzar en la solución de fondo a problemas estructurales como la concentración de la tierra y el acceso con sus productos a los mercados de alimentos.

\section{La coyuntura 2015-2017}

Mauricio Macri asume como Presidente de la Nación Argentina el 10 de diciembre de 2015 (hasta la actualidad), candidato de la alianza Cambiemos. Tras su asunción se produjo la eliminación de las retenciones para el trigo, el maíz, la carne y una reducción del 35 al 30\% en el caso de la soja. Según un informe del Instituto de Estudios sobre la Realidad Argentina y Latinoamericana (2015), el Decreto 133/ 2015 que puso fin a las retenciones, implicó para las arcas públicas un costo fiscal de 3.685 millones de dólares y una transferencia directa de esos recursos a las grandes corporaciones agropecuarias. Asimismo, se puso fin a las limitaciones para la compra de moneda extranjera y se flexibilizaron los requisitos para importar.

Durante los primeros meses del 2016 el gobierno de Macri procedió a disolver el Registro Nacional de Trabajadores y Empleadores Agrarios (Renatea) ${ }^{9}$, creado

\footnotetext{
9 En rigor, fue la Corte Suprema la que a finales de 2015 confirmó un fallo de la justicia que declaraba inconstitucional la creación del RENATEA. A través de este dictamen, la corte dejó el camino preparado para que el gobierno de Cambiemos ponga en marcha nuevamente el Renatre para las tareas de fiscalización del empleo en el sector rural, un organismo que vuelve a funcionar bajo la órbita de la Unión Argentina de Trabajadores Rurales y Estibadores (UATRE), que estuvo caracterizado por cierta desidia frente a situaciones de precariedad laboral entre los peones rurales.
} 
en el 2012 y que llevaba adelante la tarea de fiscalización del empleo en el sector rural. En los últimos tres años, el Renatea había fiscalizado 1780 establecimientos rurales, registrando a más de 154 mil trabajadores y realizando más de mil denuncias de trata, explotación laboral e infantil (Página 12, 2016a).

Asimismo, el 2 de julio de 2016 mediante un decreto se flexibilizan los parámetros de control para la venta de propiedades rurales a extranjeros. Si bien la medida no modificó los límites para la extranjerización como el tope del 15 por ciento del territorio nacional y el máximo de 1000 hectáreas en zona núcleo o equivalente, el decreto desarticuló una serie de exigencias administrativas que debían cumplir los inversores extranjeros y cambió el porcentaje de propiedad a nombre de un extranjero (del $25 \%$ al $51 \%$ ) requerido para que una sociedad sea considerada extranjera y sea pasible de aplicación de la norma (Ámbito Financiero, 2016). De este modo, el Poder Ejecutivo ofrece alternativas para eludir, a través de maniobras contables, las limitaciones y obligaciones dispuestas en la norma (Página 12, 2016b).

Algunos gestos presidenciales fueron interpretados como un claro apoyo a los sectores ligados a los grandes empresarios del campo, por ejemplo, cuando después de 14 años de ausencias presidenciales Macri se hizo presente en la exposición de la Sociedad Rural en Julio 2016. En aquella oportunidad, el mandatario afirmó que "El campo es mucho más que lo que puede producir, es más que los impuestos que puede pagar, es nuestra historia y emblema". Este gesto político del Presidente de la Nación tiene una enorme carga simbólica de reconocimiento del poder de la oligarquía terrateniente pampeana (CEPA, 30 de marzo de 2017).

Una las principales medidas del gobierno de Macri fue la reconversión del Ministerio de Agricultura, Ganadería, Pesca y Alimentación al Ministerio de Agroindustria. La nueva denominación elimina de las ramas primarias de la economía destacando solo al sector agroindustrial. Algunos puntos de la ley de presupuesto votada en 2016 dan cuenta de la direccionalidad señalada. La Ley № 27.341 que reglamenta el presupuesto nacional votado en el Congreso de la Nación en su artículo 71 determina un presupuesto global para el Ministerio de Agroindustria de $\$ 4.500$ millones (160 millones de dólares aproximadamente), de los cuales, $\$ 1.000$ millones (casi el 23\%) corresponden a compensaciones para la producción de soja en las provincias del norte argentino.
Otro indicio de la mirada del gobierno nacional actual respecto al modelo de desarrollo rural lo constituye el proceso de despidos llevado adelante en la Secretaría de Agricultura Familiar, el desfinanciamiento de sus programas, el cambio de rango a Subsecretaría y la reciente fusión de dicho organismo con la Secretaría de Control y Desarrollo Territorial. Al respecto, la UTT ${ }^{10}$ denunció que el Gobierno ha dejado a la Secretaría de Agricultura Familiar paralizada, sin presupuesto y sin políticas públicas para la agricultura familiar (Rofi, 2017a).

Por otro lado, y como parte de la política energética implementada por el gobierno de Macri, se comenzaron a eliminar gran parte de los subsidios estatales a los servicios públicos energéticos: agua potable y saneamiento, energía eléctrica e hidrocarburos (gas combustible y petróleo). En efecto, los aumentos de tarifas resultaron muy altos en varios de los servicios públicos, aumentado los costos de producción de la industria nacional y con un impacto muy importante para las Pequeñas y Medianas Empresas (PyMEs). En el ámbito rural esta medida también tuvo impactos negativos ya que afectó a los pequeños y medianos productores de sectores como el vitivinícola que usan bombas eléctricas para el agua de riego (Letcher, 2016).

Tras dar de baja a 880 grupos de Cambio Rural ${ }^{11}$ en julio de 2017, en septiembre del mismo año, el ministro de Agroindustria, Ricardo Buryaile, recortó el histórico programa Cambio Rural que brindaba asistencia técnica a medianos y pequeños productores. Este cambio de orientación modifica el segmento de destinatarios, excluyendo a la agricultura familiar. Entre los requisitos que se exigen a quienes quieran formar parte de esta nueva versión de Cambio Rural se incluye "ser nacido en territorio argentino o ser hijo de ciudadano nativo". Con esta disposición, quedan excluidos una parte significativa de los productores bolivianos del Cinturón Verde del Gran La Plata, que abastecen el consumo de verduras y hortalizas al conurbano bonaerense (La Nación, 11/09/2017). Otro requisito del programa establece como condición: "Desarrollar la actividad productiva y/o de servicios con carácter exclusivamente comercial". De este

10 La Unión de Trabajadores de la Tierra (UTT) forma parte de la Confederación de Trabajadores de la Economía Popular (CTEP). Aunque cuenta con presencia en 15 provincias.

11 El programa Cambio Rural, que había sido creado en 1993 y relanzado en 2014, incluía a la agricultura familiar en transición hacia la capitalización y tenía como uno de sus impulsar el agregado de valor. 
modo se excluye a aquella porción de los agricultores familiares donde la propia producción tiene una doble función autoabastecimiento y excedentes para el mercado.

En respuesta a las acciones e inacciones del gobierno de Cambiemos, el 3 de octubre de 2017, los pequeños productores de verdura realizaron un "Feriazo" en diferentes puntos del país a modo de protesta para denunciar que el Gobierno Nacional no atiende las demandas de este sector del campo. En el "Feriazo" se vendieron verduras al precio de quinta (el precio que los agricultores cobran por sus productos), ya que uno de los objetivos del reclamo fue visibilizar el bajo valor que se les paga a los productores, en contraste con el precio al cual los productos llegan al consumidor final.

"Somos quienes producimos más del 65 por ciento de los alimentos que comemos día a día en nuestras casas (...) A pesar de la dignidad de nuestro trabajo, las condiciones en las que vivimos, producimos y comercializamos son muy precarias". Productor de la Unión de Trabajadores de la Tierra (Extraído del Periódico Página 12, 02/10/2017).

En la misma línea, en un comunicado de presa de la UTT que se dio a conocer a propósito del "Feriazo", se señaló que "No somos el campo rico que produce commodities para la exportación. No especulamos con nuestra producción, ni guardamos alimento en silos para vender cuando mejor se pague" (Página 12, 2017). Además, los pequeños productores agropecuarios denunciaron que el Ministerio de Agroindustria no tomó "ni una sola medida que favorezca al campo pobre que produce alimentos para el pueblo" (Infobae, 2017).

\section{Reflexiones finales}

La necesidad de extender el lente temporal en el análisis de la situación actual de la agricultura familiar en Argentina no pretende proporcionar un relato histórico integral. Por el contrario, consiste en esbozar un enfoque útil para los estudios sociales agrarios, basado en la identificación de ciertos aspectos de la historia agraria significativos para la compresión del presente. En otras palabras, la preocupación principal de este trabajo no estuvo puesta en la historia agraria per se, sino en determinadas dimensiones que podrían servir para un examen de la coyuntura actual.
Así, y desde una mirada de largo plazo, se examinaron las continuidades y discontinuidades en las políticas agrarias, identificando los momentos en que se superponen, tensionan, refuerzan y/o se debilitan determinados modelos de desarrollo rural. Lo cual no fue planteado en términos lineales, sino en términos de imágenes en movimiento (Wald, 2016).

Reconstruir esta trayectoria de largo plazo permite analizar sus impactos en el desarrollo institucional, normativo y programático actual, revisar el alcance y las marcas de las sucesivas coyunturas críticas en que se forjan las políticas y ponderar sus efectos (Incháustegui et al., 2010).

De esta forma, es posible observar que las políticas públicas sobre agricultura familiar constituyen un anclaje de indagación sobre los logros, las debilidades y materias pendientes de la acción colectiva. Estas son subsidiarias tanto de los marcos discursivos que sobre el sector han construido las organizaciones, como de su capacidad para introducirlos en la arena pública en el contexto de las luchas contra la invisibilidad y marginalidad, explorando sus potenciales para un modelo de desarrollo rural alternativo. Como sostiene Shore (2010) a partir del análisis de las políticas públicas es posible reconocer cómo ciertas gubernamentalidades (como lo son las categorías utilizadas para definir la población objetivo o grupos destinatarios de las intervenciones), moldean los modos de vida de los actores sociales involucrados, y viceversa.

En ese marco, es posible concluir que existen elementos para sostener que el paradigma neoliberal ha logrado persistir en la Argentina, de forma directa o indirecta, y a pesar de los cambios de gobierno. En efecto, las políticas públicas agrarias han buscado favorecer principalmente a la agricultura capitalista a gran escala y orientada a la exportación de commodities.

Por un lado, se señaló que desde 1955 se tomaron diferentes medidas macroeconómicas que socavaron las bases del modelo ISI. Sin embargo, fue con la última dictadura cívico militar, profundizado posteriormente por los gobiernos de Carlos Menem, que el modelo neoliberal sentó su hegemonía, la cual aún continúa. Luego, durante los doce años de gobiernos kirchneristas, si bien se adoptó una postura crítica al Consenso de Washington, esto no significó que haya existido un avance claro en desmontar el andamiaje neoliberal.

Finalmente, se observa como el gobierno de Macri ha dado un golpe de timón, favoreciendo con sus medidas a 
las grandes corporaciones agropecuarias, y desarticulando gran parte de las políticas para la agricultura familiar de base campesina en las que se había avanzado.

En este sentido, tal como lo señala Morresi (2015), si bien es cierto que el neoliberalismo estuvo en crisis en América Latina en general (y en Argentina en particular), se trató de una crisis profunda que todavía no está resuelta. Consecuentemente, la agricultura familiar muy probablemente deberá enfrentar otro período más donde sea visto como sector relegado para el modelo de desarrollo agrario nacional.

Finalmente, resulta interesante reflexionar sobre el hecho que, desde tiempos coloniales, los países de América Latina se caracterizaron por ser economías con una baja diversificación productiva relativa y una alta concentración de sus exportaciones en sectores extractivos y recursos primarios (Altomonte \& Sánchez, 2016). Esto ha llevado a que la región sea particularmente vulnerable a los ciclos económicos que experimentan la demanda de bienes primarios y los términos de intercambio con los países desarrollados.

Argentina ha demostrado no ser ajena a este proceso, y a través de su historia, ha disfrutado de importantes períodos de bonanza exportadora gracias a sus recursos naturales (agropecuarios fundamentalmente). Sin embargo, no le ha resultado sencillo convertir estos períodos de bonanza en impulsos efectivos para consolidar sus procesos de desarrollo a largo plazo.

\section{Referências}

Alonso, M. E., \& Vázquez, E. C. (2008). Historia Argentina contemporánea (1880-1930): la economía primaria exportadora: del régimen oligárquico a los gobiernos radicales. Buenos Aires: Aique Grupo Editor.

Altomonte, H., \& Sánchez, R. J. (2016). Hacia una nueva gobernanza de los recursos naturales en América Latina y el Caribe. Santiago de Chile: CEPAL.

Ámbito Financiero. (2016, julio 1). Gobierno cambió la Ley de Tierras y flexibilizó venta de campos a extranjeros. Buenos Aires. Recuperado el 18 de diciembre del 2017, de http: / / www.ambito.com / 845514-gobierno-cambio-la-ley-detierras-y-flexibilizo-venta-de-campos-a-extranjeros

Ansaldi, W. (1992). Frívola y casquivana, mano de hierro en guante de seda: una propuesta para conceptualizar el término oligarquía en América Latina. Cuadernos del CLAEH, 17(61), 43-48.
Aranda, D. (2012, octubre 25). Semillas en debate. Buenos Aires: Página 12. Recuperado el 13 de octubre del 2017, de https:/ / www.pagina12.com.ar/diario/ sociedad/3-206295-2012-10-25.html

Argentina. Presidencia de la Nación Argentina. (2011). PEA: Plan Estratégico Agroalimentario y Agroindustrial Participativo y Federal 2010-2016. Argentina: Ministerio de Agricultura, Ganadería y Pesca.

Azpiazu, D., Basualdo, E. M., \& Khavisse, M. (2005). El nuevo poder económico en la Argentina de los ochenta. Buenos Aires: Siglo XXI.

Basualdo, E. M. (2006). Estudios de historia económica argentina desde mediados del siglo XX a la actualidad. Buenos Aires: Siglo XXI.

Borras, S., Kay, C., Gómez, S., \& Wilkinson, J. (2013). Land grabbing and global capitalist accumulation: key features in Latin America. Canadian Journal of Development Studies, 4(33), 402-416.

Carballo González, C., Boucau, F., \& Moreira, C. (2012). Plan estratégico agroalimentario y agroindustrial 2010-2020. Desafíos crecientes para un desarrollo rural sustentable. In Anales del XVI Jornadas Nacionales de Extensión Rural y VIII del Mercosur. Concordia: AADER-CEISO.

Castellani, A. G. (2006). Los ganadores de la 'década perdida'. La consolidación de las grandes empresas privilegiadas por el accionar estatal. Argentina 19841988. In A. Pucciarelli (Ed.), Los años de Alfonsín iEl poder de la democracia o la democracia del poder? Buenos Aires: Siglo XXI.

De Dios, R. (1999). Políticas activas de desarrollo sustentable para la pequeña producción agropecuaria en Argentina. Revista Trabajo y Sociedad, 1(1), 1-12.

Ferrer, A. (2005). La economía argentina. Buenos Aires: Fondo de Cultura Económica.

Foro Nacional de la Agricultura Familiar-FONAF. (2006). Documento elaborado por las organizaciones representativas del sector productor agropecuario familiar. Mendoza: SAGPyA, PRODERNOA.

Gerchunoff, P., \& Torre, J. C. (1996). La política de liberalización económica en la administración de Menem. Desarrollo Economico, 143(36), 733-768.

Gigena, A., Gómez, F., Weinstock, A. M., Oyharzábal, E., \& Ota, D. (2013). Relevamiento y sistematización de problemas de tierra de los agricultores familiares en la Argentina. Buenos Aires: Ministerio de Agricultura, Ganadería y Pesca de la Nación.

Gras, C., \& Hernández, V. (2010). Renta, conocimiento e identidad: el estatus de la tierra en el nuevo modelo y las disputas por sus funciones. In V. Hernández (Ed.). Trabajo, conflictos y dinero en un mundo globalizado (pp. 227-258). Buenos Aires: Biblos. 
Gudynas, E. (2009). Diez tesis urgentes sobre el nuevo extractivismo. In Centro Andino de Acción Popular - CAAP. Centro Latinoamericano de Ecología Social CLAES (Eds.), Extractivismo, política y sociedad (Cap. VII, pp. 187-225). Quito, Ecuador.

Incháustegui, T., Olivares, E., \& Riquer, F. (2010). Del dicho al hecho: análisis y evaluación de la política de acceso de las mujeres a una vida libre de violencia en México (2000-2009). Ciudad de México: Comisión Nacional para Prevenir y Erradicar la Violencia Contra las Mujeres.

Infobae. (2017, octubre 3). Productores de verduras protestan con un "feriazo" en la Plaza de Mayo. Buenos Aires: Infobae. Recuperado el 5 de noviembre del 2017, de https:// www.infobae.com/economia/2017/10/03/productoresagrarios-protestan-con-un-feriazo-en-la-plaza-de-mayo

Instituto de Estudios sobre la Realidad Argentina y Latinoamericana - IERAL. (2015). Informe de coyuntura del IERAL (Vol. 24, No. 958). Buenos Aires: IERAL. Recupera el 18 de septiembre del 2017, de http: / / www.ieral.org/ images_db/noticias_archivos/3292-Informe $\% 20 \mathrm{de} \% 20$ Coyuntura.pdf

Jacoby, E. (2012). The best food on earth. Peru: as good as it gets. World Nutrition, 3(7), 294-306.

Jara, C. E. (2016). ¿Qué es un campesino? La construcción de un sujeto político ambiguo en Santiago del Estero (Argentina). Astrolabio, (16), 340-361.

Jara, C., Rodríguez Sperat, R., \& Rincón Manrique, F. (2014). La agricultura familiar en el desarrollo rural: continuidades y rupturas del paradigma neoliberal en Argentina y Colombia. Revista Nera, 17(24), 86-106.

Kay, C. (2001). Los paradigmas del desarrollo rural en América Latina. In Asociación de Geógrafos Españoles (Ed.), El mundo rural en la era de la globalización: incertidumbres y potencialidades (pp. 337-430). Lleida: Universitat de Lleida.

Kay, C. (2009). Estudios rurales en América Latina en el periodo de globalización neoliberal ¿Una nueva ruralidad? Revista Mexicana de Sociologia, 4(71), 607-645.

Lattuada, M., Nogueira, M. E., \& Urcola, M. (2015). Tres décadas de desarrollo rural en Argentina: continuidades y rupturas de intervenciones públicas en contextos cambiantes (1984-2014). Buenos Aires: Tesseo.

Letcher, H. (2016). Heterogéneo y regresivo: el impacto del cambio en las economías regionales. Buenos Aires: Comisión de Economía Política Argentina. Recuperado el 16 de septiembre del 2017, de http:/ / centrocepa.com.ar/ informe-sobre-economias-regionales-mayo-2016/

López, A. (2006). Empresarios, instituciones y desarrollo económico: el caso argentino. Buenos Aires: UN-CEPAL.

Manzanal, M., \& Schneider, S. (2011). Agricultura familiar y políticas de desarrollo rural en Argentina y Brasil: análisis comparativo 1990-2010. Revista Interdisciplinaria de Estudios Agrarios, 34, 35-71.
Márquez, S. (2007). Un año de Foro: crónica, realizaciones y perspectivas del ejercicio de diálogo político desarrollada por el Foro Nacional de la Agricultura Familiar. Buenos Aires: PROINDER.

McMichael, P. (2009). A food regime genealogy. The Journal of Peasant Studies, 1(36), 139-169.

Montero, A. S., \& Vincent, L. (2013). Del" peronismo impuro" al" kirchnerismo puro": la construcción de una identidad política hegemónica durante la presidencia de Néstor Kirchner en Argentina (2003-2007). Postdata, 18(1), 123-157 Recuperado en 24 de junio de 2019, de http: / / www. scielo.org.ar/scielo.php?script=sci_arttext\&pid=S185196012013000100005\&lng=es\&tlng=es

Morresi, S. D. (2011). Las raíces del neoliberalismo argentino (1930-1985). In M. A. Rossi \& A. López (Eds.), Crisis y metamorfosis del Estado Argentino: el paradigma neoliberal en los noventa. Buenos Aires: Ediciones Luxemburg.

Morresi, S. D. (2015). La persistencia del neoliberalismo en la argentina: más allá de la propuesta republicana. Épocas: Revista de Ciencias Sociales y Crítica Cultural, 1(1).

Nogueira, M. E., Urcola, M. A., \& Lattuada, M. (2017). La gestión estatal del desarrollo rural y la agricultura familiar en Argentina: estilos de gestión y análisis de coyuntura 2004-2014 y 2015-2017. Revista Latinoamericana de Estudios Rurales, 2(4), 23-59.

Novaro, M. (2006). Historia de la Argentina contemporánea: de Perón a Kirchner. Buenos Aires: Edhasa.

Oszlak, O. (1997). La formación del Estado Argentino: elementos conceptuales e históricos (Cap. 1). Buenos Aires: Editorial Planeta.

Página 12. (2016a, mayo 16). A pedir de los patrones rurales. Buenos Aires. Recuperado el 5 de noviembre del 2017, de https:/ / www.pagina12.com.ar/diario/ elpais / 1-299445-2016-05-16.html

Página 12. (2016b, julio 2). Abren la tranquera para eludir la ley de tierras. Buenos Aires. Recuperado el 17 de noviembre del 2017, de https:/ / www.pagina12.com. ar/ diario/ economia/2-303227-2016-07-02.html

Página 12. (2017, octubre 2). Feriazo en Plaza de Mayo. Buenos Aires. Recuperado el 18 de diciembre del 2017, de https: / / www.pagina12.com.ar/66555-feriazo-enplaza-de-mayo

Paz, R. (2006). ¿Desaparición o permanencia de los campesinos ocupantes en el noroeste argentino? Evolución y crecimiento en la última década. Canadian Journal of Latin American and Caribbean Studies, 31(61), 169-197.

Pesce, J. (2006). Política y economía durante el primer año del gobierno de Alfonsín. In A. Pucciarelli (Ed.), Los años de Alfonsín. ¿El poder de la democracia o la democracia del poder? Buenos Aires: Siglo XXI.

Rapoport, M. (2006). Historia política y económica de la Argentina (1880-2003) (Cap. 3). Buenos Aires: Ariel. 
Rodríguez Enríquez, C., \& Reyes, M. F. (2006). La política social en la Argentina post-convertibilidad: políticas asistenciales como respuesta a los problemas de empleo (Documento de Trabajo, No. 55). Buenos Aires: Centro Interdisciplinario para el Estudio de Políticas Públicas.

Rodríguez Sperat, R. (2015). ¿Representa el capital un limitante para la productividad en la Agricultura Familiar? Un estudio de caso en Santiago del Estero. Cayapa: Revista Venezolana de Economía Social, 27(14), 9-34.

Rodríguez Sperat, R., Paz, R. G., Suarez, V., \& Díaz, J. P. (2015). Construyendo mercados desde la propia finca: tres experiencias sobre circuitos cortos en la agricultura familiar. Revista AgroSur, 1(43), 3-17.

Rofi, D. (2017a, octubre 2). "Feriazo" en Plaza de Mayo: agricultores familiares venderán verduras al valor que reciben en las quintas. Buenos Aires: La Nacion. Recuperado el 18 de diciembre del 2018, de http:/ / www.lanacion. com.ar/2068088-feriazo-en-plaza-de-mayo-venderanverduras-hortalizas-y-frutas-a-los-precios-en-las-quintas

Romero, L. A. (2006). Sociedad democrática y política democrática en la Argentina del siglo XX. Buenos Aires: Bernal.

Rouquié, A. (2000). América Latina: introducción al extremo occidente. México: Siglo XXI Editores.

Roze, J. P. (1992). Conflictos agrarios en la Argentina: el proceso liguista (2 vols.). Buenos Aires: Centro Editor de América Latina.
Shejtman, A., \& Berdegué, J. (2004). Desarrollo territorial rural. Santiago del Chile: RIMISP.

Shore, C. (2010). La antropología y el estudio de la política pública: reflexiones sobre la "formulación" de las políticas públicas. Antípoda, (10), 21-49.

Slutzky, D. (2008). Situaciones problemáticas de tenencia de la tierra en Argentina (Serie Estudios e Investigaciones, No. 14). Buenos Aires: PROINDER. Recuperado el 12 de junio del 2008, de http: / / redaf.org.ar/noticias / wpcontent/ uploads / 2008/08/problematicasde-tenenciade-la-tierra.pdf

Svampa, M. S. (2009). La disputa por el Desarrollo: territorios y lenguajes de valoración. In Cambio de Época (Ed.), Movimiento social y poder político (1. ed., pp. 93-114). Buenos Aires: Siglo Veintiuno Editores.

Van der Ploeg, J., Jingzhong, Y., \& Schneider, S. (2012). Rural development through the construction of new, nested, markets: comparative perspectives from China, Brazil and the European Union. The Journal of Peasant Studies, 1(39), 133-173.

Varesi, G. (2014). La construcción de la hegemonía kirchnerista en Argentina (2003-2007) (Temas y Debates, No. 28, pp. 57-80). Rosario: UNR.

Vidal, M. (2008). Napalpí: la herida abierta (4. ed.). Córdoba: El Fauno.

Wald, N. (2016). Historical paths to current unrest: extending the temporal lens in analysing geographies of agrarian change and conflict. Geoforum, (76), 38-47. 